\title{
Fundamental Studies on Etioporphyrin Removal from Model Oil Using Toluene Assisted Ionic Liquids
}

\author{
Nor Faizatulfitri Binti Salleh ${ }^{1,2}$, Muhammad Syafiq Hazwan Bin Ruslan ${ }^{2,3,4^{*}}$, Aysraf Hanim Ab Rahim ${ }^{1,2}$, Lim Zu Jian ${ }^{1}$, \\ Fathin Nabilah Binti Azmee ${ }^{1}$, Khafnini Khanafiah ${ }^{1}$, Suzana Yusup ${ }^{1}$, and Pradip Chandra Mandal ${ }^{5}$ \\ ${ }^{1}$ Department of Chemical Engineering, Universiti Teknologi PETRONAS, 32610 Seri Iskandar, Perak, Malaysia \\ ${ }^{2}$ Centre of Research in Ionic Liquids, Institute of Contaminant Management, Universiti Teknologi PETRONAS, 32610 Seri Iskandar, \\ Perak, Malaysia. \\ ${ }^{3}$ School of Chemical Engineering, College of Engineering, Universiti Teknologi MARA, 40450 Shah Alam, Selangor, Malaysia. \\ ${ }^{4}$ Centre of Lipids Engineering and Applied Research, Ibnu Sina Institute of Scientific and Industrial Research, Universiti Teknologi \\ Malaysia, 81310 Johor Bharu, Johor, Malaysia. \\ ${ }^{5}$ Titas Gas Transmission and Distribution Co. Ltd, 105 Kazi Nazrul Avenue, Kawran Bazar, Dhaka 1215, Bangladesh.
}

\begin{abstract}
The surging demand for unconventional oil has driven the research initiative to extract heavy metals from heavy crude oil to ease the upgrading processes and produce lighter-ends hydrocarbon to be supplied in the field of transportation and petrochemical industry. Despite multiple methods have been discovered for metal removal, the low efficiency removal had enlightened the need of using ionic liquids. Three ionic liquids are studied in this project which are 1-butyl-3methylimidazolium octylsulfate (BMIMOS), 1-ethyl-3-methylimidazolium octylsulfate (EMIMOS) and 1-ethyl-3-methylimidazolium bis(trifluoromethylsulfonyl)imide $\left(\right.$ EMIMNTf $\left._{2}\right)$ on extraction of two complex heavy metals; nickel etioporphyrin and vanadium oxide etioporphyrin. The experiments were tested at temperature ranging from $30{ }^{\circ} \mathrm{C}$ to $90{ }^{\circ} \mathrm{C}$ and 30 minutes to 90 minutes of mixing time. In addition, samples were analysed through UV-Visible Spectroscopy (UV-Vis) and Fourier Transform Infrared (FTIR) to determine the effectiveness of the extraction and study the functional group presence in the samples accordingly. Results revealed the overall maximum extraction efficiency of $22 \%$ of $\mathrm{Ni}$-EP was recorded by EMIMNTf 2 . The changing in reaction temperature and time did not affect the percentage of Ni-EP removal by EMIMNTf 2 .
\end{abstract}

\section{Introduction}

The world supply for crude oil is continuously depleting due to great demand driven by dramatic globalization and industrial growth. Recently, the conversion of unconventional oil such as extra heavy oil and heavy oil into useful fractions as an alternative is highly desirable. Heavy crude oil contains long chain hydrocarbons and high fractions of heavy, high boiling point species that are enriched with heteroatoms like nitrogen $(\mathrm{N})$, oxygen $(\mathrm{O})$ and sulfur $(\mathrm{S})[1,2]$. It cannot be denied that the production of conventional oil which is also known as 'sweet crude' is highly cost-effective and assuring than unconventional oil. However, current report provided by BP predicted the world oil supply will only be exist for 53.3 years, thus it is such an important step to start using the unconventional oil source.

The heavy oils have become a hot issue towards refinery industry due to the high metal contents, asphaltenes, resins fractions, rich in nitrogen, sulfur and oxygen. The presence of heavy metals such as cobalt $(\mathrm{Co})$, copper $(\mathrm{Cu})$, nickel $(\mathrm{Ni})$ and vanadium $(\mathrm{V})$ has pose a challenge in the process of upgrading heavy oils [3]. Although heavy metals seem to appear in small concentration, it posed a great concern. The accumulation of metal contaminants on catalysts by plunging on their pores could permanently deactivate the catalyst used for desulfurization and cracking process and accelerate the corrosion at the turbine [4]. Besides, heavy metal such as vanadium is potentially being converted into vanadium peroxide during combustion thus increases the concern regarding toxic emission towards environment [5]. Jenifer et. al. stated that $\mathrm{Ni}$ and $\mathrm{V}$ are the most abundant heavy metals to be found in natural crude oil [6]. Generally, both metals are usually found as a porphyrinic structures. A common porphyrinic compound is known as metal porphyrin. A metal porphyrin formed as a metal atom displaces two central hydrogen ions which then forms a metal complex [6]. This chelated metal is highly stable thus making demetalization process extremely problematic. Thus, demetalization process is constantly being developed to improve the efficiency of heavy metals removal to enhance the productivity of oil refining industry.

Conventional demetalization process such as hydrodemetallization (HDM) has been proved to be able in extracting high percentage of heavy metals. However, the downside of this process is heavy metals tend to accumulate in the pores of HDM catalyst thus deactivate the catalyst [6]. Other than that, there are a few types of

\footnotetext{
* Corresponding author: syafiqhazwan@uitm.edu.my
} 
unconventional method has been introduced. Example of unconventional methods are microwave radiations, sonication, oxidation and electrochemical demetalization [7-9]. Although these methods are successfully extract and converting heavy metals but still offering a few disadvantages. For examples, sonication is only applicable in mild non-catalytic conditions while in oxidation, oxidant agents' effectiveness might be reduced due to side reactions that occurred simultaneously during demetalization. Therefore, the search of the best method that offers huge advantage is a crucial step for the purification of heavy oil.

Ionic liquid (ILs) is a molten salt, normally has a melting point below than $100^{\circ} \mathrm{C}$. ILs own unique properties such as low vapor pressure, non-flammable and broad liquids range [10]. Besides that, ILs also known as a versatile solvent due to the availability of various anions and cations combination thus provide wider range of physical and chemical properties according to application of interest. Vergara and co-workers reported the application of ILs with halogen-free carboxylic acid anion for various metals extraction in wastewater [11]. Their study showed that trioctylmethyl ammonium oxalate was successfully extracted $96 \%$ of copper $(\mathrm{Cu})$, nickel $(\mathrm{Ni})$, and cobalt (Co) from neutral aqueous solution. Meanwhile, Fuerhacker et. al. synthesized several ILs to remove heavy metals from activated sludge [12]. The phosphonium-based ILs have been proved to remove $90 \%$ of zinc $(\mathrm{Zn}), \mathrm{Ni}$ and lead $(\mathrm{Pb})$ from sludge. Although there were many work had been done regarding on the usage of ILs as extracting agents for heavy metal in wastewater, the application of ILs in heavy metal extraction from crude oil is rarely being reported. Recently, ILs have drawn a greater attention due to its potential as a catalyst in solvent for purification of heavy oil [13]. Our previous work had reported the removal of vanadyl oxide tetraphenyl porphyrin (VO TPP) by using toluene-assisted ILs [14]. The study shows that the combination of toluene with 1-ethyl-3methylimidazolium octylsulfate (EMIMOS) recoded the highest percentage of metal removal which is $45 \%$ at 30 minutes reaction time in temperature of $30^{\circ} \mathrm{C}$. Therefore, the study was extending to the usage of a few types of ILs in order to explore the effect of alky chain and anions towards metal porphyrin removal.

The aim of this study was to carry out the removal of nickel etioporphyrin (Ni-EP) in model oil performed in toluene environment assisted by selected imidazoliumbased ILs. In addition, the effect of ILs alkyl chain and anion at different reaction conditions were also being done. The removal efficiency of Ni-EP was analyzed by using spectrophotometer technique. To get more clear explanation regarding in the interaction between $\mathrm{Ni}$-EP and ILs, the functional groups analysis was also performed.

\section{Methodology}

\subsection{Material and Apparatus}

The chemicals used are as follow: nickel etioporphyrin (Ni-EP), 1-ethyl-3-methylimidazolium octylsulfate (EMIMOS) (790663-79-5, 98\%, Merck), 1-butyl-3methylimidazolium octylsulfate (BMIMOS) (445473-585, 95\%, Merck), 1-ethyl-3-methylimidazolium bis(trifluoromethylsulfonyl)imide (EMIMNTf $)$ (174899$82-2,97 \%$, Merck) and toluene (108-88-3, 99.5\%, Sigma). All chemicals were analytical grade and being directly used without further purification process.

\subsection{Preparation of model solutions}

Model oil solution was prepared by dissolving $0.015 \mathrm{~g}$ of $\mathrm{Ni}-\mathrm{EP}$ in $50 \mathrm{~mL}$ toluene at the temperature of $30^{\circ} \mathrm{C}$ with continuous stirring. Then, another $150 \mathrm{~mL}$ of toluene was added into the mixture in which $50 \mathrm{~mL}$ in each occasion over a certain period. As the Ni-EP was completely dissolved, the mixture was transferred into $250 \mathrm{~mL}$ volumetric flask and toluene was added until it reached the calibration mark.

\subsection{Preparation of calibration curve}

The calibration curve for Ni-EP were done by preparing metal solution in toluene into various concentration (10$100 \mathrm{ppm})$. The analysis was performed on a UV-Vis spectrophotometer from Shimadzu using a $1.25 \mathrm{~mm} \mathrm{x}$ $12.5 \mathrm{~mm} \times 45 \mathrm{~mm}$ cuvette and toluene as solvent. The samples were scanned in the range of 200-800 $\mathrm{nm}$ and the concentrations were computed by applying Lambert Beer Law. The measurement was done triplicate to ensure the accuracy.

\subsection{Removal of metal from model oil}

The removal of metals was done by applying liquid-liquid extraction technique. The mixture of IL: model oil with volume ratio (1:10) was loaded into autoclave bath reactor and heated on hot plate for 3-5 minutes for temperature equalization purpose. Then, IL/model oil mixture was heated into selected reaction temperatures; $30^{\circ} \mathrm{C}, 60^{\circ} \mathrm{C}$, and $90^{\circ} \mathrm{C}$. The sample was left to cool down at room temperatures. Then, the sample was poured into $50 \mathrm{~mL}$ separating funnel in which two layers were formed. The upper (model oil) and bottom (IL) were collected and analyzed. The experiment was also repeated by varying reaction time; 30 minutes, 60 minutes and 90 minutes.

\subsection{Analysis of the extracts}

The upper layer of the mixture containing model oil and toluene were analyzed by using Uv- Visible Spectrophotometer from Shimadzu. The samples were analyzed in the region of $200-800 \mathrm{~nm}$ and the concentration was determined according to calibration curve prepared previously. The percentage of metal removal was calculated based on the Equation 1:

$$
E=\left[\left(C_{i}-C_{f}\right) / C_{i}\right] \times 100 \%
$$


where $E$ is the percentage of metal extract, $C_{i}$ is the initial metal concentration and $C_{f}$ is the final metal concentration.

The bottom layer was collected and analyzed by using Fourier Transform InfraRed (FTIR) IS5 from Thermo Nicolet coupled with diamond Attenuated Total Reflectance (ATR). The measurement was performed in the range of $4000 \mathrm{~cm}^{-1}$ to $450 \mathrm{~cm}^{-1}$ under 16 scanning.

\section{Results and Discussion}

\subsection{Calibration Curve}

Figure 1 shows the UV-Vis spectra and calibration curve for Ni-EP. In Figure 2, the presence of three peaks can be observed. According to Pradip and co-workers, the presence of porphyrin and metal porphyrin can be identified through two bands which are S and Q band [15]. The peak in the area of $393 \mathrm{~nm}$ represents $\mathrm{S}$ band (general porphyrin) while the $\mathrm{Q}$ band (metal porphyrin) can be seen in the peak around $571 \mathrm{~nm}$ and $553 \mathrm{~nm}$. Nevertheless, the calibration curve for Ni-EP was plot based on the peak in $553 \mathrm{~nm}$ as it provides the best fit with high value of regression coefficient $\left(\mathrm{R}^{2}\right)$ of 0.9981 . The equation for calibration curve is $\mathrm{y}=0.0661 \mathrm{x}+0.038$.

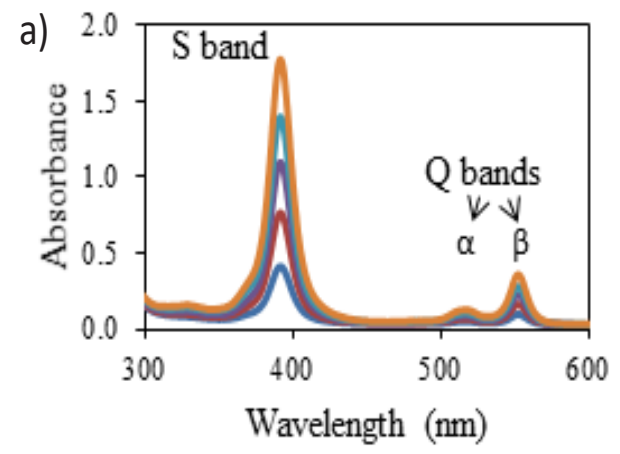

Figure 1. The absorbance of standard solutions of Ni-EP

\subsection{Effect of alkyl chain towards Ni-EP removal in model oil}

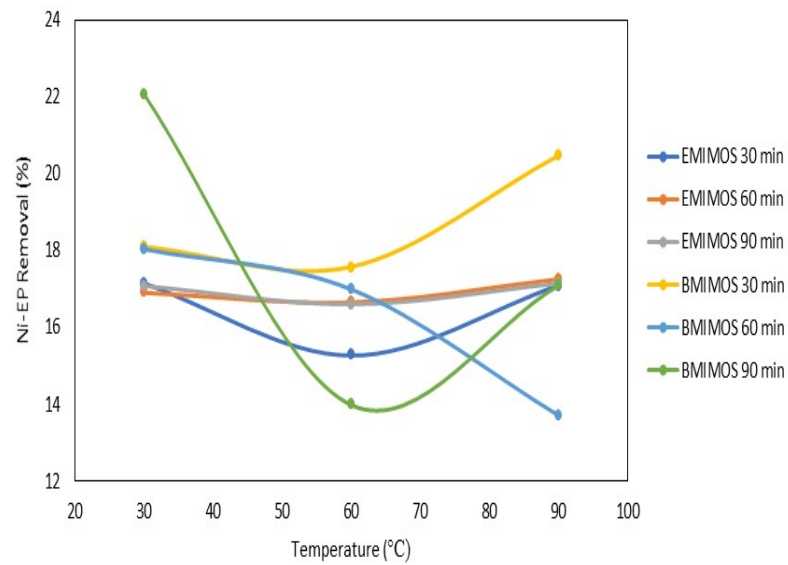

Figure 2. The percentage of Ni-EP removal in EMIMOS and BMIMOS at different mixing times and temperatures.

Figure 2 shows the percentage Ni-EP removal from model oil at various temperatures and reaction times. Analysis on UV-Vis spectra revealed that BMIMOS is a powerful catalyst in assisting toluene for removal of Ni-EP as it recorded the maximum performance of $22 \%$ at $30^{\circ} \mathrm{C}$ within 90 minutes reaction time. However, as the temperature increased to $60^{\circ} \mathrm{C}$, the efficiency of $\mathrm{Ni}$-EP removal had been reduced to $13 \%$ before slightly improved to $17 \%$ at $90^{\circ} \mathrm{C}$. For the reaction time of 60 minutes in which the percentage of Ni-EP removal had decreased from $18 \%$ to $13 \%$ as the temperature increased from 30 to 90 . The interesting trend can also be observed as the 30 minutes reaction time as the percentage of NiEP removal increased from $18 \%$ to $20 \%$ as the temperature increased from $30^{\circ} \mathrm{C}$ to $90^{\circ} \mathrm{C}$ respectively. Meanwhile, there is no trend can be observed as the EMIMOS had been employed to assist toluene in removing Ni-EP. Further analysis on percentage of Ni-EP shows that the usage of EMIMOS only able to remove up to $17 \%$ of Ni-EP at any reaction conditions as compared to BMIMOS that recorded up to $20 \% \mathrm{Ni}$-EP removal. The same result was obtained by Germani and co-workers in which the percentage of mercury extraction increased as the IL alkyl chain increased [16]. Meindersma et. al. indicated that shorter alky chain tends to be selective toward the aromatic compound due to easy substitution of $\pi$-electron at the above and below of an aromatic ring. In this case, low percentage of Ni-EP removal might be due to the high selectivity of EMIMOS towards toluene instead of metal porphyrin [17].

\subsection{Effect of anions towards removal in model oil}

Figure 3 shows the percentage Ni-EP removal by ILs with different anions from model oil at various temperatures and reaction times. The EMIMNTf $f_{2}$ proved to be a good extractant as it showed good performance in removing NiEP as it recorded the percentage of removal more than $20 \%$ in any reaction times and temperature compared to EMIMOS. Wankowski and Dietz stated that the metal ion exchange favor the hydrophobic anion [18]. Increasing anion hydrophobicity reduced the possibility of ILs dissolved in aqueous solvent thus enhancing the removal of Ni-EP. The molecular dynamic simulation carried out by Yee et. al. indicates that the IL with $\mathrm{NTf}_{2}$ anion is less likely to be dissociated compared to IL with OS anion which proving the hydrophobicity of EMIMNTf 2 [19].

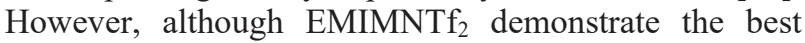
performance in removing $\mathrm{Ni}-\mathrm{EP}$, the trend is almost stagnant as the temperature and reaction time increased. This condition might be due to the IL had reaching its maximum capacity in supporting the metal ion mobility thus causing stagnant trend as shown in Figure 3. 


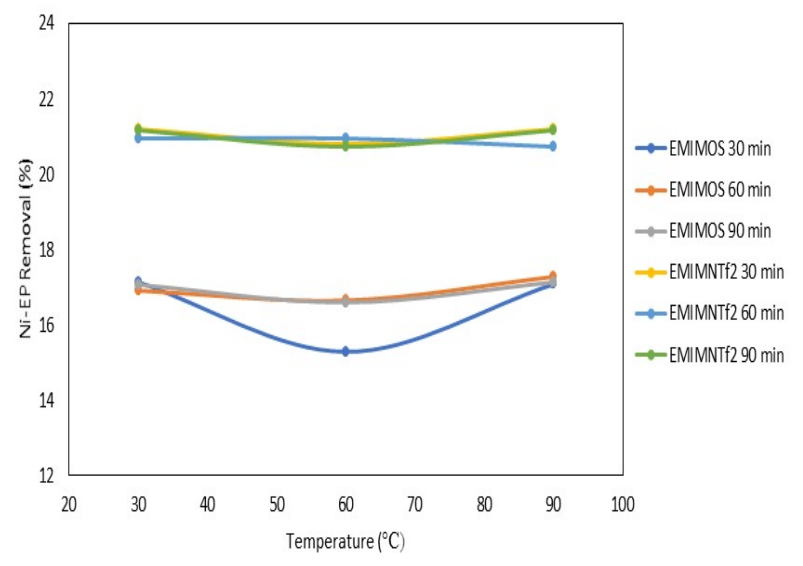

Figure 3. The percentage of Ni-EP removal in EMIMOS and EMIMNTf $_{2}$ at different mixing times and temperatures.

\subsection{FTIR Analysis}

Analysis on FTIR spectra of all samples revealed the process of demetallization could cause the addition and absence of functional groups. Figure 4 shows the FTIR spectra for BMIMOS, EMIMOS, EMIMNTf 2 and model oils. Based on Figure 4 (a) and (b), the C-H monosubstituted peak can be observed in the area of 783 $\mathrm{cm}^{-1}$ while symmetric S-O stretching vibration can be identified in the area of $1004 \mathrm{~cm}^{-1}$. The peak in the area of $1381 \mathrm{~cm}^{-1}$ was due to the present of $\mathrm{C}-\mathrm{N}$ in aromatic amine of 1-methylimidazole structure. The symmetric and asymmetric stretching of $\mathrm{C}-\mathrm{H}$ scissoring vibration of $\mathrm{CH}_{3} \mathrm{~N}^{+}$moiety was identified through the present bending at $1463 \mathrm{~cm}^{-1}$ while the present of strong stretching peak at $1557 \mathrm{~cm}^{-1}$ indicate the present of $\mathrm{S}=\mathrm{O}$ of sulfonate anion. Besides, the peak stretching at $2911 \mathrm{~cm}^{-1}$ and 2922 $\mathrm{cm}^{-1}$ is associated with the symmetric and asymmetric stretching $\mathrm{CH}_{2}$ vibration of alkyl chain.

For the spectra of samples after Ni-EP removal, the formation of new peak can be observed in the area of $1494 \mathrm{~cm}^{-1}$ indicates the presence of symmetric $\mathrm{C}=\mathrm{C}$ of porphyrin [21]. Besides, there were addition of new peaks; $692 \mathrm{~cm}^{-1}$ and $725 \mathrm{~cm}^{-1}$ which belong to C-CH-C in plane bending and $\mathrm{C}-\mathrm{H}$ out of plane bending in Ni-EP structure. Other than that, the intensity of $\mathrm{CH}_{2}$ vibration of alky chain which belong to both ILs has been reduced. This shows that the BMIMOS is capable for assist toluene in removing Ni-EP as compared to EMIMOS as IR spectra show the addition of new functional groups which in turn proving the presence of porphyrin in extractant solvent.

Figure 4 (c) illustrates the FTIR spectra for EMIMNTf $_{2}$ and samples after removal of Ni-EP. The study carried out by Kiefer and co-workers indicated that the C-H stretching around $2800-3200 \mathrm{~cm}^{-1}$ shows weak signal due to strong influence by the presence of $\mathrm{NTf}_{2}$ anion [22]. The area between $500 \mathrm{~cm}^{-1}$ to $750 \mathrm{~cm}^{-1}$ were dominated by $\mathrm{NTf}_{2}$ fingerprints. The peak at $568 \mathrm{~cm}^{-1}$ indicates the presence of $\mathrm{CF}_{3}$ asymmetric bending while $740 \mathrm{~cm}^{-1}$ is associated with $\mathrm{CF}_{3}$ symmetric bending. The
$\mathrm{S}-\mathrm{N}-\mathrm{S}$ bending can be recognized through the presence of peak at $648 \mathrm{~cm}^{-1}$ while $\mathrm{N}-\mathrm{CH}_{3}$ can be identified by the presence of peak at $1049 \mathrm{~cm}^{-1}$. The peaks stretching at $1328 \mathrm{~cm}^{-1}$ and $1345 \mathrm{~cm}^{-1}$ were designated to antisymmetric $\mathrm{SO}_{2}$.

An observation towards IR spectra for all model oil samples after extraction of Ni-EP shows the formation of new peaks in area approximately $1569-1580 \mathrm{~cm}^{-1}$ indicated the presence of $\mathrm{C}=\mathrm{C}$ belong to Ni-EP. Besides, the $\mathrm{C}-\mathrm{CH}-\mathrm{C}$ in plane bending of Ni-EP can be identified through peak at $697 \mathrm{~cm}^{-1}$. Besides, the FTIR spectra show the mixing time does not have significant impact towards the ILs structure during the extraction of Ni-EP as the spectra of ILs at different mixing time in Figure 4 almost the same.
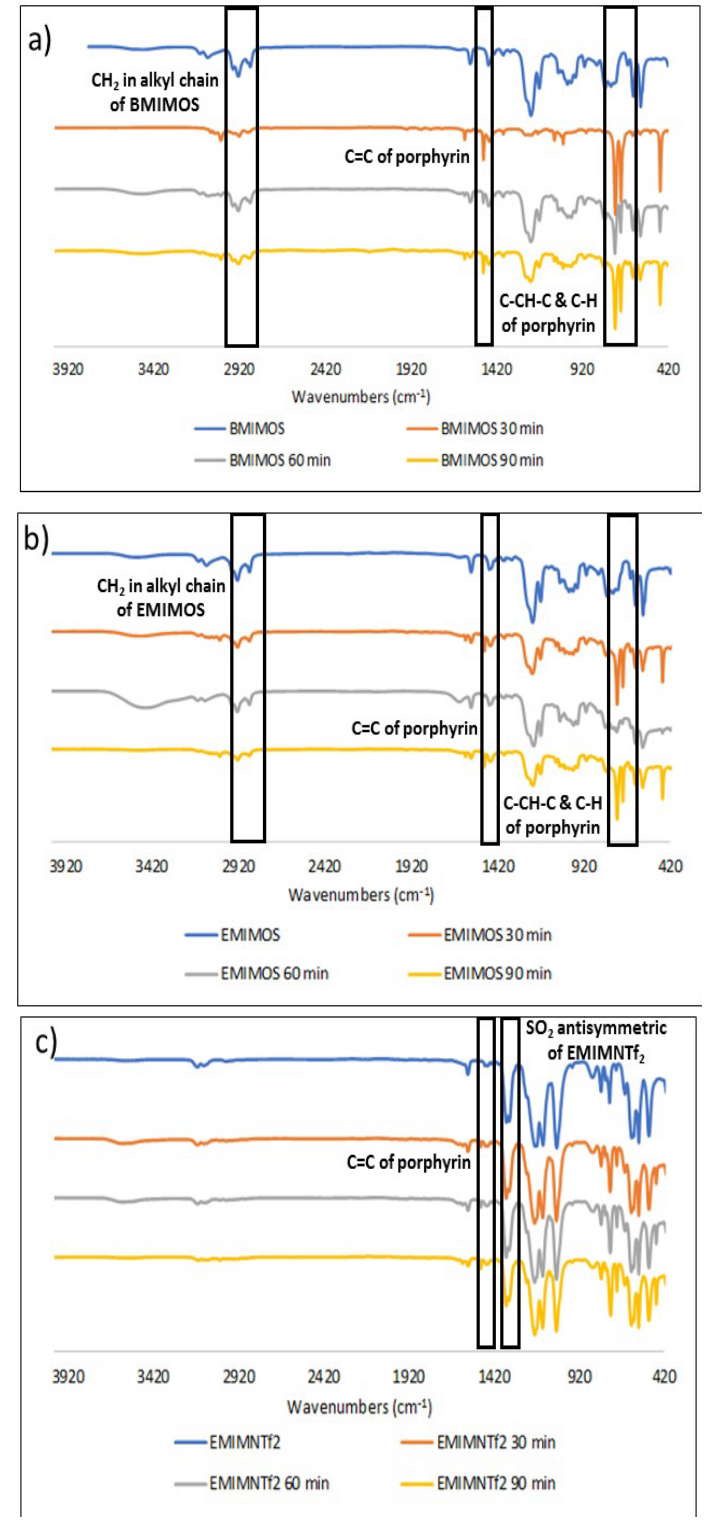

Figure 4. FTIR spectra for Ni-EP removal using: (a) BMIMOS, (b) EMIMOS, and (c) EMIMNTf EM. $_{2}$

\section{Conclusion}

This work reported the removal of Ni-EP from model oil by using toluene assist by selected imidazolium-based 
ILs. Analysis of UV-Vis absorbance had found that EMIMNTf $_{2}$ shows promising performance as it able to extract more than $20 \%$ of Ni-EP from model oil. Besides, the stagnant trend obtained proved that the removal of $\mathrm{Ni}$ EP by EMIMNTf $f_{2}$ did not affect by reaction conditions. Analysis on IR spectra for most of all samples show the present of both metal porphyrins which indicate ILs did play their role in the demetallization process.

This work was financially supported by Yayasan Universiti Teknologi PETRONAS (YUTP) 0153AA-E33. The authors also gratefully acknowledge Centre of Research in Ionic Liquids (CORIL), Universiti Teknologi PETRONAS for providing facilities in this research work.

\section{References}

[1] A.M. McKenna, J.M. Purcell, R.P. Rodgers, A.G. Marshall, Energy Fuel 23 (2009) 2122-2128.

[2] A. Demirbas, A. Bafail, A.-S. Nizami, Petrol Sci. Technol. 34 (2016) 303-308.

[3] J.O. Wilberforce, IOSR J.Pharm and Biol. Sci. 11 (2016) 43-44.

[4] L. Konne, U. Iheanetu, A. Cookey, J Material Sci. Eng. 6, 5 (2017) 1-7.

[5] P.C. Mandal, M. Sasaki, M. Goto, Fuel 92 (2012) 288-294.

[6] A.C. Jenifer, P. Sharon, A. Prakash, P.C. Sande, Energy Fuel 29 (2015) 7743-7752.

[7] S. Wang, J. Yang, X. Xu, J. Gao, Petrol Sci. Technol. 27 (2009) 368-378.

[8] K.S. Suslick, Y. Didenko, M.M. Fang, T. Hyeon, K.J. Kolbeck, W.B. McNamara III, M.M. Mdleleni, M. Wong, Philos.Trans. A Math. Phys. Eng. Sci. 357 (1999) 335-353.

[9] C. Ovalles, I. Rojas, S. Acevedo, G. Escobar, G. Jorge, L.B. Gutierrez, A. Rincon, B. Scharifker, Fuel Process Technol. 48 (1996) 159-172.

[10] J.S. Wilkes, J. Mol. Catal. A: Chemical 214 (2004) 11-17.

[11] M.A.V. Vergara, I.V. Lijanova, N.V. Likhanova, D.J. Vigueras, O.O. Xometl, Can. J. Chem. Eng. 92 (2014) 1875-1881.

[12] M. Fuerhacker, T.M. Haile, D. Kogelnig, A. Stojanovic, B. Keppler, Water Sci. Technol. 65 (2012) 1765-1773.

[13] H.-f. FAN, Z.-b. LI, T. Liang, J. Fuel Chemi. Technol. 35 (2007) 32-35.

[14] N. Salleh, N. Ishak, M. Ruslan, P. Mandal, S. Yusup, IOP Conf. Ser.: Mater. Sci. Eng., IOP Publishing (2018).

[15] P.C. Mandal, M. Sasaki, M. Goto, Fuel Process Technol. 104 (2012) 67-72.

[16] R. Germani, M.V. Mancini, G. Savelli, N. Spreti, Tetrahedron Lett. 48 (2007) 1767-1769.

[17] G.W. Meindersma, A.J. Podt, A.B. de Haan, Fuel Process Technol. 87 (2005) 59-70.

[18] J.L. Wankowski, M.L. Dietz, Solvent Extr. Ion Exc. 34 (2016) 48-59.

[19] P. Yee, J.K. Shah, E.J. Maginn, J. Phys. Chem. B 117 (2013) 12556-12566.
[20] P.C. Mandal, M. Goto, M. Sasaki, J. Jpn. Petrol. Inst. 57 (2014) 18-27.

[21] S.E.V.a.R.S.M. Roy. D. R., Acta A: Molecular and Biomolecular Spectroscopy 190 (2018) 121-128.

[22] J. Kiefer, J. Fries, A. Leipertz, Appl. Spectrosc. 61 (2007) 1306-1311. 